\title{
Viscoplastic constitutive model of P92 steel coupled with creep-fatigue damage
}

\author{
$\mathrm{Yu} \mathrm{Cao}{ }^{1}$, Xin $\mathrm{Cui}^{1}$, and Dongmei $\mathrm{Ji}^{2}$ \\ ${ }^{1}$ Affiliation not available \\ ${ }^{2}$ Shanghai University of Electric Power
}

August 27, 2020

\begin{abstract}
A new constitutive model within the framework of Chaboche model was developed by improving the nonlinear isotropic hardening law and kinematic hardening law with cyclic characteristic parameters. Strain controlled creep-fatigue experiment of P92 steel with various strain amplitudes and holding time were conducted under 600 . The feature of the cycle softening and stress relaxation were studied under the creep-fatigue condition. The result shows that the effect of strain amplitude on cyclic softening and stress relaxation behavior is negligible, however the holding time has a greater impact on both. According to the experimental data, the constitutive model of P92 under creep-fatigue interaction was deduced, and the reliability of the model was also verified, in which the cycle characteristics of P92 steel under creep-fatigue was finely described.
\end{abstract}

\section{Hosted file}

Manuscript-FATIGUE \& FRACTURE OF ENGINEERING MATERIALS \& STRUCTURES.doc available https://authorea.com/users/354339/articles/477934-viscoplastic-constitutive-model-of-
p92-steel-coupled-with-creep-fatigue-damage 